\title{
Relating NMDA Receptor Function to Receptor Subunit Composition: Limitations of the Pharmacological Approach
}

\author{
Jacques Neyton and Pierre Paoletti \\ Laboratoire de Neurobiologie, Centre National de la Recherche Scientifique, Unité Mixte de Recherche 8544, Ecole Normale Supérieure, 75005 Paris, France
}

Over 20 years of pharmacological, physiological, and genetic studies have established that NMDA receptors (NMDARs), a subtype of ionotropic glutamate receptors, play key roles in numerous physiological and pathological processes in the brain (Dingledine et al., 1999). In particular, activation of NMDARs is required for long-term potentiation (LTP) and long-term depression (LTD), the two major forms of synaptic plasticity that are proposed to underlie learning and memory. NMDARs are heterotetramers composed of NR1 and NR2(A-D) subunits (and more rarely, NR3 subunits), and their functional properties are strongly influenced by the type of NR2 subunit incorporated (Cull-Candy et al., 2001). The four NR2 subunits have distinct distributions in the CNS, with patterns of expression that change drastically during development. Whereas in the embryo, only NR2B and NR2D subunits are expressed, NR2A predominates in the adult brain, being ubiquitously expressed, whereas NR2B expression is restricted to the forebrain and NR2C is highly enriched in the cerebellum. The existence of distinct NMDAR subpopulations raises the attractive possibility that different receptor subtypes play different roles in the brain, and relating receptor subunit composition to receptor function has become a major challenge in the glutamate receptor field (Cull-Candy and Leszkiewicz, 2004).

Received Dec. 8, 2005; accepted Dec. 29, 2005.

NVP-AAM077 was kindly provided by Dr. Yves Auberson (Novartis, Basel, Switzerland). We thank Philippe Ascher and Boris Barbour for comments on this manuscript.

Correspondence should be addressed to either Jacques Neyton or Pierre Paoletti, Laboratoire de Neurobiologie, Centre National de la Recherche Scientifique, Unité Mixte de Recherche 8544, Ecole Normale Supérieure, 46 rue d'Ulm, 75005 Paris, France. E-mail: neyton@biologie.ens.fr or paoletti@biologie.ens.fr.

D01:10.1523/JNEUROSCI.5242-05.2006

Copyright $\odot 2006$ Society for Neuroscience $\quad$ 0270-6474/06/261331-03\$15.00/0
For this purpose, having subtype-selective antagonists might be of great help. This is best exemplified by ifenprodil and derivatives, a class of compounds that selectively inhibit NR2B-containing receptors and have proven useful in elucidating several roles of this receptor population in brain functions and dysfunctions (Cull-Candy and Leszkiewicz, 2004). Recently, Auberson et al. reported the discovery of a new NMDAR antagonist [ $\left(1 R S, 1^{\prime} S\right)$-PEAQX (Auberson et al., 2002) and its active diastereoisomer $[(R)$ - $[(S)$-1-(4-bromophenyl)-ethylamino] - (2,3-dioxo-1,2,3,4tetrahydroquinoxalin - 5 - yl ) - methyl]phosphonic acid (NVP-AAM077) (Liu et al., 2004)] claimed to display strong selectivity for NR2A-containing receptors $(>100$ fold preferential blockade for NR2A- vs NR2B-containing receptors). Using this compound, a number of groups have attempted to dissect out the roles of NMDAR subtypes in synaptic plasticity, but conflicting results have been obtained. On one hand, Liu et al. (2004) and Massey et al. (2004) presented striking data showing that LTP induction is specifically dependent on activation of NR2A-containing receptors, whereas LTD requires activation of NR2Bcontaining receptors. On the other hand, Berberich et al. (2005), Weitlauf et al. (2005), and Toyoda et al. (2005) obtained evidence for a much more complex situation, in which both receptor subtypes are able to generate LTP and/or LTD. Facing this confused situation, one wonders: is the pharmacological approach to relate function to subunit composition really flawless? In this commentary, we first present data showing that NVP-AAM077 displays much less subunit selectivity than originally described. Then, in a more general perspective, we highlight several limitations of the available selective drugs against NMDARs.
NVP-AAM077 discriminates poorly between NR2A- and NR2B-containing receptors

In their study of NVP-AAM077 potency on recombinant human NMDARs, Liu et al. (2004) compared the effect of NVPAAM077 on NR1a/NR2A and NR1a/ NR2B receptors activated by applying glutamate at 2 and $5 \mu \mathrm{M}$, respectively. The authors state that these concentrations were chosen to obtain similar levels of receptor activation $(80 \%$ of the maximum response; see their Fig. S1). This is surprising, given the vast amount of literature that consistently shows that glutamate has a higher affinity for NR1a/NR2B than for NR1a/N2A receptors (Laurie and Seeburg, 1994; Mori and Mishina, 1995; Priestley et al., 1995; Cull-Candy et al., 2001). Thus, to achieve a similar level of activation, glutamate should be applied at a higher concentration at NR1a/NR2A receptors than at NR1a/NR2B receptors. Because NVP-AAM077 is proposed to act as a competitive antagonist (Auberson et al., 2002; Liu et al., 2004), we wondered whether the large difference in $\mathrm{IC}_{50}$ seen between NR1a/NR2A receptors and NR1a/NR2B receptors (14 vs 1800 nM, respectively) was caused in part by a difference in glutamate occupancy of both receptor subtypes. Using rodent NMDARs expressed in Xenopus oocytes, we performed experiments similar to those of Liu et al. (2004) but used glutamate concentrations of $5 \mu \mathrm{M}$ at NR1a/NR2A receptors and $2 \mu \mathrm{M}$ at NR1a/NR2B receptors, very close to their respective glutamate $\mathrm{EC}_{50}$ values (4.8 and $1.8 \mu \mathrm{M}$ in our recording conditions). As shown in Figure 1, in such conditions, NVP-AAM077 IC $_{50}$ values now differ by only approximately ninefold between the two receptor subtypes ( 213 vs $23 \mathrm{~nm}$ ), far from the $\sim 130$ fold difference reported by Liu et al. (2004). Our results are in close agreement 
with the $\sim 12$-fold difference found by Feng et al. (2004) using ( $\left.1 R S, 1^{\prime} S\right)$ PEAQX as well as with the results recently obtained by Berberich et al. (2005) and Weitlauf et al. (2005) using NVPAAM077 on transfected human embryonic kidney cells. Thus, at least in rodents, NVP-AAM077 discriminates poorly between NR2A- and NR2B-containing receptors, and there is no concentration range that allows full inhibition of NR1a/ NR2A receptors while leaving NR1a/ $\mathrm{NR} 2 \mathrm{~B}$ receptors unaffected. It must be remembered that NVP-AAM077 is also a powerful antagonist of NR2C- and NR2D-containing receptors (Feng et al., 2004). Finally, and this is a general concern for all competitive antagonists, the inhibition produced by NVP-AAM077 will depend strongly on the effective glutamate concentration, which is generally unknown in physiological experiments and which is likely to differ form one stimulation protocol to the other. In conclusion, NVP-AAM077 appears not to satisfy the requirements that are expected for a truly NR2A-selective antagonist.

\section{Subtype-selective antagonists do exist, but they have limitations}

Several agents are known to selectively inhibit certain of the NMDAR subtypes. As already mentioned, the best-characterized and most widely used series of such agents are ifenprodil and derivatives such as Ro 25-6981 [R- $\left(R^{*}, S^{*}\right)-\alpha$-(4-hydroxyphenyl)- $\beta$-methyl-4-(phenyl-methyl)-1-piperidine propanol] and CP 101,606 [(1S,2S)-1-(4-hydroxyphenyl)-2-(4-hydroxy-4-phenylpiperidino)-1-propanol]. These synthetic compounds antagonize NR1/NR2B receptors with $>200$-fold preference for these receptors compared with NR1/2A, NR1/2C, or NR1/2D receptors (Williams, 1993; Mott et al., 1998). Furthermore, they act both in a noncompetitive and voltage-independent manner so that they retain full efficacy under conditions of high glutamate concentrations and depolarized membrane potentials, as often encountered during intense neuronal activity. There are, however, three limitations when using ifenprodil (or a derivative). First, ifenprodil inhibits NMDARs only at high glutamate concentration $\left(>\mathrm{EC}_{50}\right)$. This is because of the fact that ifenprodil, in addition to its inhibitory effect, also produces an increase in the receptor affinity for glutamate. At very low glutamate concentrations, this latter effect dominates resulting in a net potentiating effect of NMDA responses by ifenprodil (Kew et al., 1996). In that respect, special

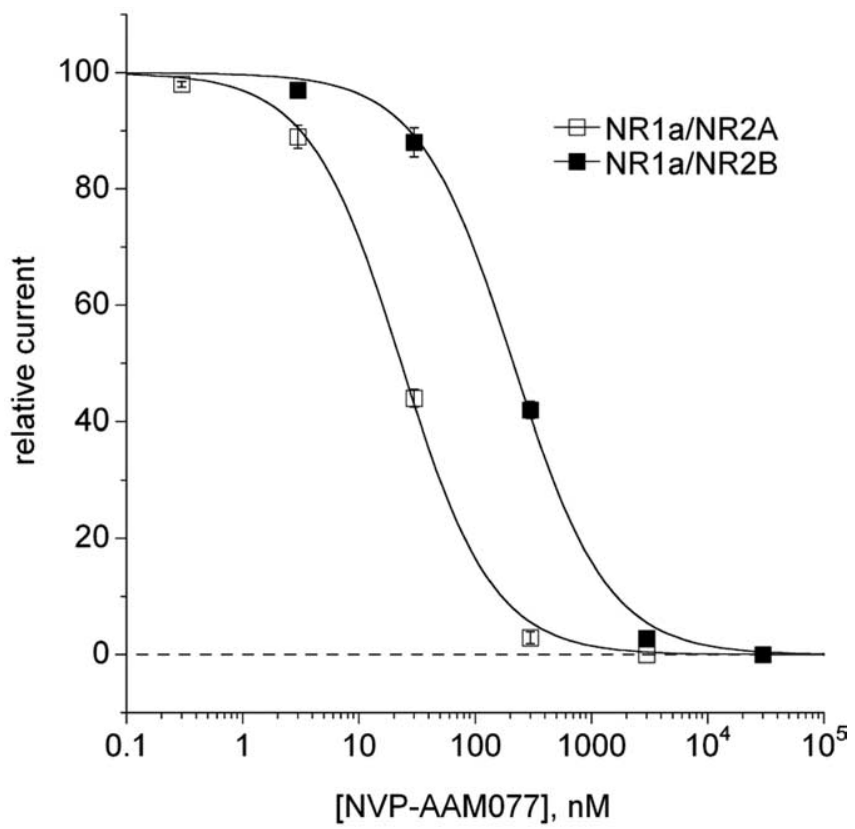

Figure 1. NVP-AAM077 discriminates poorly between NR2A-and NR2B-containing receptors. Concentration-response curves showing NVP-AAM077 inhibition of rodent NR1a/NR2A and NR1a/NR2B receptors expressed in Xenopus 0ocytes, as described by Perin-Dureau et al. (2002), are shown. NMDAR currents were elicited at $-60 \mathrm{mV}$ using glycine at a saturating concentration (100 $\mu \mathrm{M})$ and glutamate at a concentration close to $\mathrm{EC}_{50}(5 \mu \mathrm{m}$ for NR1a/NR2A and $2 \mu \mathrm{m}$ for NR1a/NR2B receptors). NVP-AAM077 was applied during an application of glutamate plus glycine. The inhibition was quantified once the response in NVP-AAM077 had reached steady state. The curves represent least-square fits to the data points using the following equation: $I_{\text {rel }}=100-100 /$ $\left(1+\left(\mathrm{IC}_{50} /[\mathrm{NVP}-\mathrm{AAM} 077]\right)^{n}\right)$. The estimated values of $\mathrm{IC} \mathrm{C}_{50}$ and $n$ values are: $23 \mathrm{~nm}$ and $1.10 \mathrm{for}$ NR1a/NR2A receptors and $213 \mathrm{~nm}$ and 1.07 for NR1a/NR2B receptors. Each point is the mean value obtained form five to eight cells. NVP-AAM077 stock solutions (1 $\mathrm{mm}$ and $100 \mu \mathrm{M}$ ) were prepared by progressive dilutions with bidistilled water of a solution containing $10 \mathrm{~mm}$ NVP-AAM077 in 100 $\mathrm{mm} \mathrm{NaCl}$. Error bars represent SD.

care should be taken when studying physiological processes that involve extrasynaptic NMDARs, because these receptors may be endogenously exposed only to low glutamate concentrations. The second limitation is that at selective concentrations ( $\leq 1 \mu \mathrm{M}$ ), ifenprodil inhibits at most $80 \%$ of the response carried by NR1/ NR2B receptors. The third limitation is that, as discussed below, ifenprodil not only affects NR1/NR2B receptors but also triheteromeric NR1/2A/2B receptors.

An antagonist selective for NR2Acontaining receptors also exists: it is the zinc ion. $\mathrm{Zn}^{2+}$ is highly potent at inhibiting NR1/NR2A responses (in the nanomolar range), displays strong selectivity for NR2A-containing receptors over all other NR1/NR2 combinations ( $>100$ fold) (Paoletti et al., 1997; Traynelis et al., 1998; Rachline et al., 2005), and, similarly to ifenprodil, acts in a noncompetitive manner by binding to a modulatory N-terminal domain (Paoletti et al., 2000; Perin-Dureau et al., 2002). $\mathrm{Zn}^{2+}$, however, has some drawbacks too: first, at selective concentrations ( $\leq 200 \mathrm{~nm}$ ), it produces only partial inhibition $(\sim 70 \%)$; second, and similarly to ifenprodil, $\mathrm{Zn}^{2+}$ appears also to affect triheteromeric
NMDARs (see below); and third, it interacts with many other synaptic targets besides NMDARs (Smart et al., 2004), a property that restricts its usefulness as a pharmacological tool to study NMDARs in slices or in vivo. It remains that the particularly high zinc sensitivity of NR1/2A receptors can be used as a distinctive criterion to differentiate between NR2Aand NR2B-containing synaptic NMDARs (Kumar and Huguenard, 2003).

Finally, a competitive antagonist that displays some selectivity for NR2C- or NR2D- over NR2A- or NR2B-containing receptors has been described [PPDA; (士)-cis-1-(phenanthren-2yl-carbonyl)-piperazine-2,3-dicarboxylic acid] (Feng et al., 2004), but, as for NVP-AAM077, its selectivity factor $(<10$-fold $)$ remains weak.

\section{The problem of the existence of triheteromeric NMDARs}

There is compelling evidence that not all brain NMDARs consist of a simple binary combination of NR1 with only one type of NR2 (or NR3) subunit. Receptors incorporating two different NR2 subunits represent a sizeable fraction of native NMDARs. Triheteromeric NR1/2A/2B 
receptors are present in the cortex and hippocampus and NR1/2A/2C and NR1/ $2 \mathrm{~B} / 2 \mathrm{D}$ in the cerebellum (Cull-Candy and Leszkiewicz, 2004). Until recently, little was known about the action of subunitselective agents (ifenprodil, zinc) on triheteromeric receptors, and for that reason, triheteromeric receptors were usually ignored. The possibility that the process under scrutiny had been erroneously assigned to a particular NMDAR subtype was then left open. The pharmacology of triheteromeric NMDARs has been characterized recently. The rule is the following: a single copy of NR2A (or NR2B) is sufficient to confer high affinity to zinc (or ifenprodil), but the maximal level of inhibition is greatly reduced compared with diheteromeric receptors containing two copies of the same NR2 subunit (Hatton and Paoletti, 2005). In other words, a low ifenprodil sensitivity does not necessarily mean that NR2B subunits are absent, but instead that they may preferentially coassemble with other NR2 subunits. A way to distinguish between these two possibilities could be to measure zinc sensitivity in parallel: a concomitant low Zn sensitivity will be in favor of a preponderance of triheteromeric receptors, whereas a high $\mathrm{Zn}$ sensitivity will argue for the absence of NR2B subunits.

In conclusion, for all the reasons listed above, some precaution must be taken in the interpretation of data obtained using pharmacological tools against NMDARs. There is little doubt that discrete tasks are performed by different NMDAR subtypes, but the enticing view that each NMDAR subtype has a unique and exclusive role in synaptic plasticity is likely to be an oversimplification. Given the complexity of NMDAR molecular organization (multiple possibilities of heteromeric assembly), relating function to NMDAR subtype will remain a difficult task for which additional pharmacological tools are needed. In particular, "good" organic NMDAR antagonists highly selective for
NR2A-containing receptors (and NR2Cand NR2D-containing receptors) are still eagerly awaited.

\section{References}

Auberson YP, Allgeier H, Bischoff S, Lingenhoehl K, Moretti R, Schmutz M (2002) 5-Phosphonomethylquinoxalinediones as competitive NMDA receptor antagonists with a preference for the human $1 \mathrm{~A} / 2 \mathrm{~A}$, rather than $1 \mathrm{~A} / 2 \mathrm{~B}$ receptor composition. Bioorg Med Chem Lett 12:1099-1102.

Berberich S, Punnakkal P, Jensen V, Pawlak V, Seeburg PH, Hvalby O, Kohr G (2005) Lack of NMDA receptor subtype selectivity for hippocampal long-term potentiation. J Neurosci 25:6907-6910.

Cull-Candy SG, Leszkiewicz DN (2004) Role of distinct NMDA receptor subtypes at central synapses. Sci STKE 2004:re16.

Cull-Candy SG, Brickley S, Farrant M (2001) NMDA receptor subunits: diversity, development and disease. Curr Opin Neurobiol 11:327-335.

Dingledine RJ, Borges K, Bowie D, Traynelis SF (1999) The glutamate receptor ion channel. Pharmacol Rev 51:1-61.

Feng B, Tse HW, Skifter DA, Morley R, Jane DE, Monaghan DT (2004) Structure-activity analysis of a novel NR2C/NR2D-preferring NMDA receptor antagonist: 1-(phenanthrene-2carbonyl) piperazine-2,3-dicarboxylic acid. Br J Pharmacol 141:508-516.

Hatton CJ, Paoletti P (2005) Modulation of triheteromeric NMDA receptors by $\mathrm{N}$-terminal domain ligands. Neuron 46:261-274.

Kew JN, Trube G, Kemp JA (1996) A novel mechanism of activity-dependent NMDA receptor antagonism describes the effect of ifenprodil in rat cultured cortical neurones. J Physiol (Lond) 497:761-772.

Kumar SS, Huguenard JR (2003) Pathway-specific differences in subunit composition of synaptic NMDA receptors on pyramidal neurons in neocortex. J Neurosci 23:10074-10083.

Laurie DJ, Seeburg PH (1994) Ligand affinities at recombinant $\mathrm{N}$-methyl-D-aspartate receptors depend on subunit composition. Eur J Pharmacol 268:335-345.

Liu L, Wong TP, Pozza MF, Lingenhoehl K, Wang Y, Sheng M, Auberson YP, Wang YT (2004) Role of NMDA receptor subtypes in governing the direction of hippocampal synaptic plasticity. Science 304:1021-1024.

Massey PV, Johnson BE, Moult PR, Auberson YP, Brown MW, Molnar E, Collingridge GL, Bashir ZI (2004) Differential roles of NR2A and NR2B-containing NMDA receptors in cortical long-term potentiation and longterm depression. J Neurosci 24:7821-7828.

Mori H, Mishina M (1995) Structure and function of the NMDA receptor channel. Neuropharmacology 34:1219-1237.

Mott DD, Doherty JJ, Zhang S, Washburn MS, Fendley MJ, Lyuboslavsky P, Traynelis SF, Dingledine R (1998) Phenylethanolamines inhibit NMDA receptors by enhancing proton inhibition. Nat Neurosci 1:659-667.

Paoletti P, Ascher P, Neyton J (1997) Highaffinity zinc inhibition of NMDA NR1-NR2A receptors. J Neurosci 17:5711-5725.

Paoletti P, Perin-Dureau F, Fayyazuddin A, Le Goff A, Callebaut I, Neyton J (2000) Molecular organization of a zinc binding $\mathrm{N}$-terminal modulatory domain in a NMDA receptor subunit. Neuron 28:911-925.

Perin-Dureau F, Rachline J, Neyton J, Paoletti P (2002) Mapping the binding site of the neuroprotectant ifenprodil on NMDA receptors. J Neurosci 22:5955-5965.

Priestley T, Laughton P, Myers J, Le Bourdelles B, Kerby J, Whiting PJ (1995) Pharmacological properties of recombinant human $\mathrm{N}$-methylD-aspartate receptors comprising NR1a/ NR2A and NR1a/NR2B subunit assemblies expressed in permanently transfected mouse fibroblast cells. Mol Pharmacol 48:841-848.

Rachline J, Perin-Dureau F, Le Goff A, Neyton J, Paoletti P (2005) The micromolar zincbinding domain on the NMDA receptor subunit NR2B. J Neurosci 25:308-317.

Smart TG, Hosie AM, Miller PS (2004) $\mathrm{Zn}^{2+}$ ions: modulators of excitatory and inhibitory synaptic activity. The Neuroscientist 10:432-442.

Toyoda H, Zhao MG, Zhuo M (2005) Roles of NMDA receptor NR2A and NR2B subtypes for long-term depression in the anterior cingulate cortex. Eur J Neurosci 22:485-494.

Traynelis SF, Burgess MF, Zheng F, Lyuboslavsky P, Powers JL (1998) Control of voltageindependent zinc inhibition of NMDA receptors by the NR1 subunit. J Neurosci 18:6163-6175.

Weitlauf C, Honse Y, Auberson YP, Mishina M, Lovinger DM, Winder DG (2005) Activation of NR2A-containing NMDA receptors is not obligatory for NMDA receptor-dependent long-term potentiation. J Neurosci 25: 8386-8390.

Williams K (1993) Ifenprodil discriminates subtypes of the $\mathrm{N}$-methyl-D-aspartate receptor: selectivity and mechanisms at recombinant heteromeric receptors. Mol Pharmacol 44: 851-859. 